\title{
ÉPOCA DE MATURAÇÃO, DISPERSÃO, COLHEITA E QUALIDADE FISIOLÓGICA DE SEMENTES DE SEMPRE-VIVA (Syngonanthus elegans (Bong.) Ruhland)
}

\author{
Maturation time, dispersion, crop and physiological quality of star flowers \\ (Syngonanthus elegans (Bong.) Ruhland) seeds
}

\author{
Ubirajara Russi Nunes ${ }^{1}$, Silvia Cristina Paslauski Nunes ${ }^{3}$, Valter Carvalho de Andrade Júnior ${ }^{1}$, \\ Sebastião Lourenço de Assis Júnior² ${ }^{2}$ Fábio Henrique Alves Bispo ${ }^{4}$
}

\begin{abstract}
RESUMO
Neste trabalho, objetivou-se avaliar a época de maturação, dispersão, colheita e a qualidade fisiológica de sementes de sempreviva (Syngonanthus elegans (Bong.) Ruhland), em Diamantina, MG. Capítulos de S. elegans foram colhidos em cinco épocas (20/06/ 05, 20/07/05, 20/08/05, 20/09/05 e 20/10/05) em três locais de produção natural, dentro do Campus da UFVJM em um Neossolo Quartzarênico Órtico Típico (locais 1 e 2) e Neossolo Quartzarênico Hidromórfico Típico (local 3) e, posteriormente, submetidos a testes para avaliação do vigor e germinação das sementes. A qualidade fisiológica de sementes de $S$. elegans variou em função da época e local de colheita. Estratégias de manejo devem ser realizadas como a colheita após o início do período de dispersão das sementes (junho a outubro) e com os capítulos totalmente abertos.
\end{abstract}

Termos para indexação: Vigor, germinação, floricultura.

\begin{abstract}
The aims of this work were to evaluate the maturation time, dispersion, crop and the physiological quality seeds of star flowers (Syngonanthus elegans (Bong.) Ruhland), in Diamantina, MG. S. elegans Chapters were picked up in five times (20/06/05, 20/07/05, 20/ 08/05, 20/09/05 and 20/10/05) in three places of natural production, inside the Campus of UFVJM in a Neossolo Quartzarênico Órtico Típico (places 1 e 2) and Neossolo Quartzarênico Hidromórfico Típico (place 3) and after submitted to the germination and vigor tests. Physiological quality of seeds of S. elegans were affected by time and crop place. Crop management should be accomplished as the harvest after the beginning of the period of dispersion of seeds (june to october) and with the chapters totally open.
\end{abstract}

Index terms: Vigor, germination, floriculture.

(Recebido em 8 de novembro de 2006 e aprovado em 19 de junho de 2007)

\section{INTRODUÇÃO}

Nos campos rupestres de altitude da Cadeia do Espinhaço onde se situa o Município de Diamantina o cultivo de plantas ornamentais, conhecidas como "sempreviva" constitui-se em importante atividade econômica para a população seguindo-se à mineração de diamantes que ainda persiste na Região. Sempre-viva é o nome genérico dado às flores que após serem colhidas, conservam a cor e a forma por um período mais longo de tempo, o que lhes confere alto valor comercial, principalmente no mercado internacional. Em conseqüência do extrativismo desordenado dessa atividade, sem considerar questões ecológicas e de manejo cultural, espécies de sempre-vivas estão sendo extintas de seu ambiente natural (MENDONÇA \& LINS, 2000) e colocando em risco a diversidade da flora, podendo resultar no encerramento dessa alternativa de exploração. Entre as sempre-vivas mais comercializadas na região predominam espécies da família Eriocaulaceae do gênero Syngonanthus com grande variedade de hábito e diversidade morfológica entre elas (GIULIETTI et al., 1988). Dentro deste gênero a Syngonanthus elegans (Bong.) Ruhland, conhecida popularmente como pé-de-ouro, foi a que mais contribuiu no montante de flores comercializadas (GIULIETTI et al., 1988; SCATENA et al., 1996) e, por tal motivo é uma das espécies com maior perigo de extinção (MENDONÇA \& LINS, 2000).

\footnotetext{
'Engenheiros Agrônomos, Doutores, Professores Adjunto - Departamento de Agronomia - Universidade Federal dos Vales do Jequitinhonha e Mucuri/ UFVJM - Rua da Glória, 187 - Centro - 39100-000 - Diamantina, MG - russinunes@yahoo.com.br; vcajr@yahoo.com.br

${ }^{2}$ Engenheiro Florestal, Doutor, Professor Adjunto - Departamento de Agronomia - Universidade Federal dos Vales do Jequitinhonha e Mucuri/UFVJM Rua da Glória, 187 - Centro - 39100-000 - Diamantina, MG - assisjunior@yahoo.com.br

${ }^{3}$ Mestranda em Produção Vegetal - Departamento de Agronomia - Universidade Federal dos Vales do Jequitinhonha e Mucuri/UFVJM - Rua da Glória, 187 - Centro - 39100-000 - Diamantina, MG - spaslauski@yahoo.com.br

${ }^{4}$ Engenheiro Agrônomo - Departamento de Agronomia - Universidade Federal dos Vales do Jequitinhonha e Mucuri/UFVJM - Rua da Glória, 187 Centro - 39100-000 - Diamantina, MG - fhab@bol.com.br
} 
Segundo Giulietti et al. (1996) o tamanho das populações naturais das sempre-vivas tem diminuído drasticamente em razão da coleta indiscriminada, somados ao fato de algumas espécies apresentarem distribuição restrita e as inflorescências serem removidas antes da produção de sementes. Dessa forma, seria interessante o conhecimento do período de produção e de dispersão, assim como da qualidade fisiológica das sementes em diferentes períodos para viabilizar estratégias de colheita desta espécie. Para Eriocaulaceae são apresentados trabalhos para diversos gêneros: Actinocephalus (ORIANI et al., 2005; SANO, 2004); Paepalanthus (COAN et al., 2002; SCATENA \& ROSA, 2001) e Eriocaulon (SCATENA et al., 1999b). As poucas informações sobre Syngonanthus relatam resultados referentes à anatomia (SCATENA et al., 2004; SCATENA \& MENEZES, 1996); à morfologia (SCATENA et al., 1996) e à germinação (OLIVEIRA \& GARCIA, 2005).

Objetivou-se neste trabalho avaliar a época de produção, dispersão, colheita e a qualidade fisiológica de sementes de sempre-viva (Syngonanthus elegans (Bong.) Ruhland), em Diamantina, MG.

\section{MATERIAL E MÉTODOS}

O trabalho foi desenvolvido no ano de 2005, na Universidade Federal dos Vales do Jequitinhonha e Mucuri

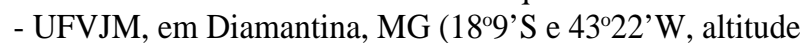
média de $1.296 \mathrm{~m}$, temperatura média anual de $18,1^{\circ} \mathrm{C}$ ). Os dados de precipitação pluviométrica, referentes ao período do trabalho e as médias entre 1971 a 1990 foram coletados na Estação Meteorológica de Diamantina (INMET, 2006), e descritos na Figura 1.

Trezentos capítulos de S. elegans foram coletados manualmente em três locais de produção natural, em parcelas com $500 \mathrm{~m}^{2}$ de extensão, em cada local, dentro do Campus da UFVJM. Os locais 1 e 2 possuem um Neossolo Quartzarênico Órtico Típico, textura arenosa, extremamente drenado, ácido, com baixos teores de matéria orgânica, e de nutrientes $\left(\mathrm{Ca}^{2+}, \mathrm{Mg}^{2+}, \mathrm{K}^{+}\right.$e $\left.\mathrm{P}\right)$, baixa CTC, com elevados teores de $\mathrm{Al}^{3+}$. O local 3 encontra-se em um Neossolo Quartzarênico Hidromórfico Típico, textura arenosa, ácido, com médios teores de matéria orgânica, e baixos valores de nutrientes, baixa CTC, com significativos teores de $\mathrm{Al}^{3+}$. O relevo plano condiciona o acúmulo de água no solo por grande parte do ano (EMBRAPA, 2006).

Os locais 1 e 2 corresponderam a parcelas distantes $1.000 \mathrm{~m}$ entre si, próximos ao Córrego Soberbo que corta o Campus. Estas áreas não continham afloramento de rochas e o solo apresentava-se bem drenado. O local 3 correspondeu à área próxima à Rodovia BR 367, apresentando afloramento de rochas, constantemente úmido e distante $2.000 \mathrm{~m}$ dos locais $1 \mathrm{e} 2$.

$\mathrm{Na}$ colheita foram utilizados alguns procedimentos que visam à preservação das espécies: foram colhidas flores (capítulos) totalmente abertas em vez de fechadas, que impedem o semeio natural; as flores foram colhidas individualmente, evitando o arranquio da touceira, a fim de preservar alguns botões abertos para semeio natural, garantindo safras futuras.

Foram realizadas oito colheitas nos três locais de produção. Iniciou-se a primeira em 20/04/05 e a segunda um mês após a primeira (20/05/05) e, assim, sucessivamente (20/06/05, 20/07/05, 20/08/05, 20/09/05 e 20/10/05), até a última colheita (20/11/05). Após cada colheita, os capítulos correspondendo cada local de colheita a um lote, foram acondicionados em sacos de papel Kraft, e secados à temperatura ambiente no Laboratório de Sementes da UFVJM até apresentar teor de umidade entre 10 e $11 \%$ (base úmida). As sementes foram extraídas friccionandose levemente os capítulos com uma espátula sobre placas de Petri, sendo separadas, posteriormente, com o auxílio de microscópio estereoscópio. Na primeira colheita (20/ 04/05) não havia sementes formadas, o que foi constatado pela observação dos ovários vazios (não fertilizados). $\mathrm{Na}$ segunda (20/05/05) as sementes já estavam formadas, no entanto, apresentavam-se ainda imaturas (coloração verde). $\mathrm{Na}$ terceira $(21 / 06 / 05)$ as sementes estavam maduras (tom avermelhado e livres entre sí) e facilmente dispersas quando friccionada com espátula. Da terceira até a sétima colheita foram feitas as avaliações da qualidade fisiológica das sementes. Na última colheita (20/11/05) não havia mais sementes nos capítulos.

Em seqüência cada amostra de sementes foi submetida aos testes para verificação do vigor e da germinação utilizando-se a metodologia proposta por Kraus et al. (1996) e adaptada: 100 sementes de cada lote (local de coleta) foram colocadas em placas de Petri (quatro repetições de 25 sementes), forradas com papel filtro umedecido com água destilada e ensacadas com sacos transparentes de polietileno. Em seguida, as placas de Petri foram levadas para câmara de germinação com 24 horas de luz por dia $\left(30 \mathrm{mmol} \cdot \mathrm{m}^{-2} \cdot \mathrm{s}^{-1}\right.$ de iluminância) à $25^{\circ} \mathrm{C}$. A germinação foi avaliada com auxílio de microscópio estereoscópio, utilizando-se como critério de referência a emergência do eixo embrionário (OLIVEIRA \& GARCIA, 2005). A germinação constou da percentagem de plântulas normais realizadas em duas contagens. A primeira contagem das plântulas foi realizada com vinte dias e a segunda com quarenta dias do início do teste. Para vigor foi considerado o registro da percentagem de plântulas normais, ocorridas 


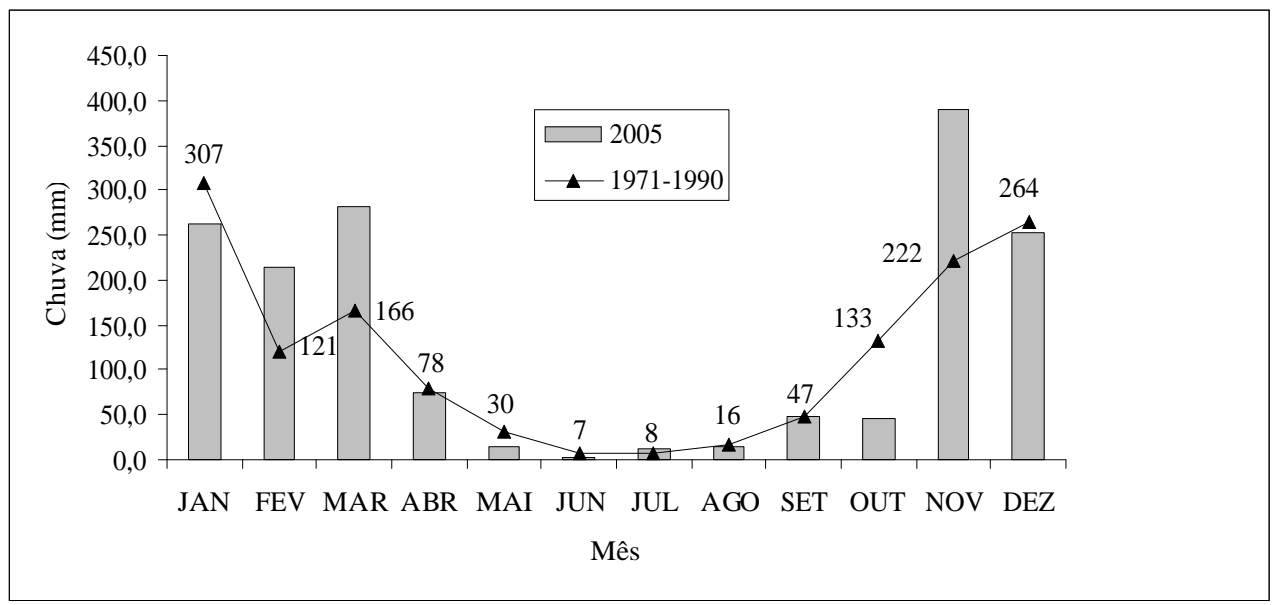

Figura 1 - Distribuição mensal da chuva em Diamantina, MG, durante o período de estudo.

vinte dias após a implantação do teste de germinação (BRASIL, 1992). Para avaliação do vigor e da germinação nas demais épocas de colheita foram realizados os mesmos procedimentos relatados anteriormente.

O delineamento experimental utilizado foi o inteiramente casualizado, no esquema fatorial ( 5 x 3 ), ou seja, época de colheita x local de colheita. Os dados de germinação e vigor foram previamente transformados em arco-seno $\sqrt{\% / 100}$, para análise estatística. As comparações entre as médias foram feitas mediante a aplicação do teste de Tukey ao nível de $5 \%$ de probabilidade.

\section{RESULTADOS E DISCUSSÃO}

Os resultados obtidos no teste de vigor e germinação estão apresentados nas Figuras 2 e 3 . Houve diferença entre locais e épocas de colheita com respostas variadas para vigor e germinação. A época que proporcionou os maiores valores de vigor e germinação foi aquela em que as sementes foram colhidas em 20/10/05 (Figuras 2 e 3).

Nos locais 1 e 2 as sementes apresentaram maiores valores de vigor (35 e 44\%) e de germinação (35 e 44\%) quando foram colhidas em 20/10/05. Observa-se que, apesar dos valores serem relativamente baixos no início das colheitas, houve aumento progressivo da taxa de vigor e germinação durante a fase de produção de sementes para esses dois locais. Para o local 3 os maiores valores de vigor $(17 \%)$ e germinação (17\%) foram obtidos quando as sementes foram colhidas em 19/07/05. A partir dessa data houve decréscimo nesses valores até a última colheita (Figuras 2 e 3). As sementes que não germinaram em todos os testes apresentaram-se mortas ou firmes. Segundo
Paixão-Santos et al. (2003) a observação da morfologia de $S$. mucugensis conduz à idéia da não existência de tegumento endurecido nas sementes, entretanto, em conseqüência da dificuldade de germinação da espécie é provável a existência de camada impermeável que impossibilita a embebição das sementes. Oliveira \& Garcia (2005) e Scatena et al. (1996) trabalhando com S. elegans obtiveram percentagens de germinação de $75 \%$ e $80 \%$, respectivamente, em temperaturas de 20 a $30^{\circ} \mathrm{C}$, portanto, valores muito acima dos encontrados no presente trabalho.Um dos possíveis fatores que pode ter influenciado esta diferença seria a temperatura utilizada no teste de germinação $\left(25^{\circ} \mathrm{C}\right)$. Entretanto, Oliveira \& Garcia (2005) comprovaram que a $25^{\circ} \mathrm{C}$ a germinação obtida (72\%) não diferiu das percentagens de germinação nas demais temperaturas utilizadas. Bedê (2002) em trabalho realizado em São Gonçalo do Rio Preto, MG, obteve taxas de germinação inferiores a $40 \%$ em todos os tratamentos utilizando temperaturas constantes de 15 a $30^{\circ} \mathrm{C}$.

A diferença na resposta germinativa entre épocas e locais de colheita pode decorrer do fato de que no local 3 o solo apresentava-se constantemente úmido (Neossolo Quartzarênico Hidromórfico Típico), o que pode ter contribuído para o rápido desenvolvimento das plantas e, com isso, a maturação das sementes se processou mais cedo. Na montagem dos testes observou-se claramente que as sementes colhidas em 19/07/05 apresentavam-se com a coloração avermelhada, indicando serem sementes maduras e bem formadas (OLIVEIRA \& GARCIA, 2005). A partir desta época de colheita, para o local 3, as sementes perderam a qualidade fisiológica, iniciando o processo de envelhecimento (deterioração). 


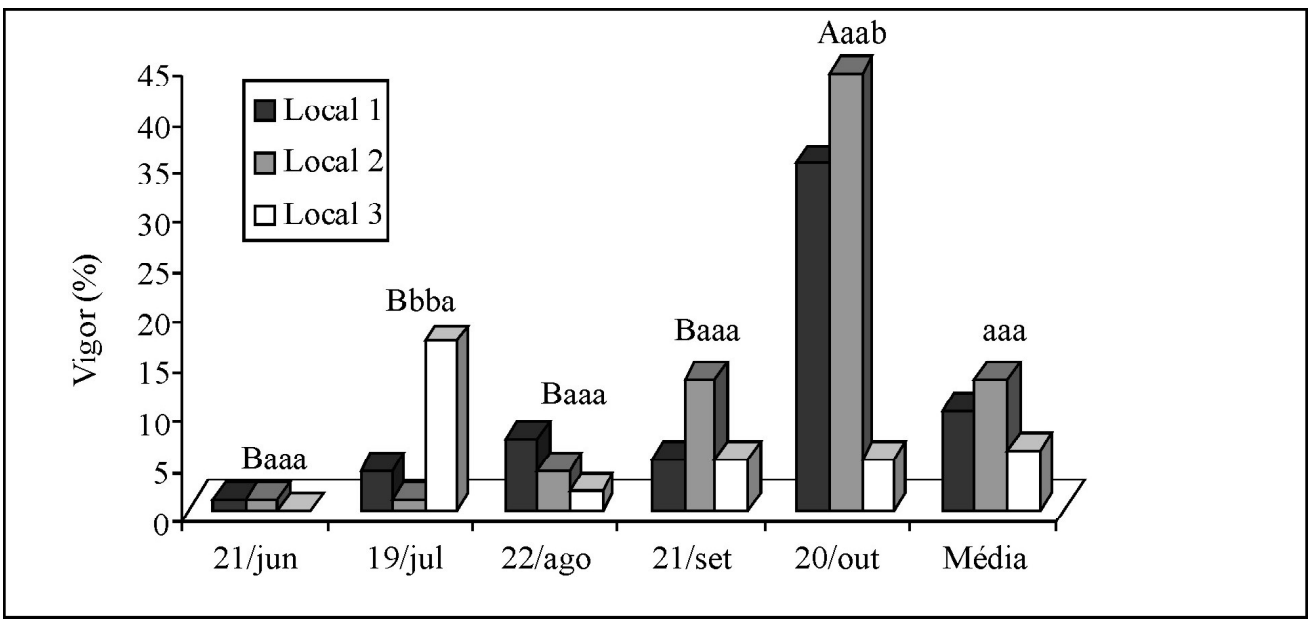

Figura 2 - Vigor de sementes de Syngonanthus elegans em função das épocas e locais de colheita. Médias seguidas pela mesma letra maiúscula entre os tratamentos de épocas de colheita e mesma letra minúscula entre os tratamentos de locais de colheita não diferem entre si $(\mathrm{P}<0,05)$, pelo teste de Tukey. Diamantina, MG, 2006.

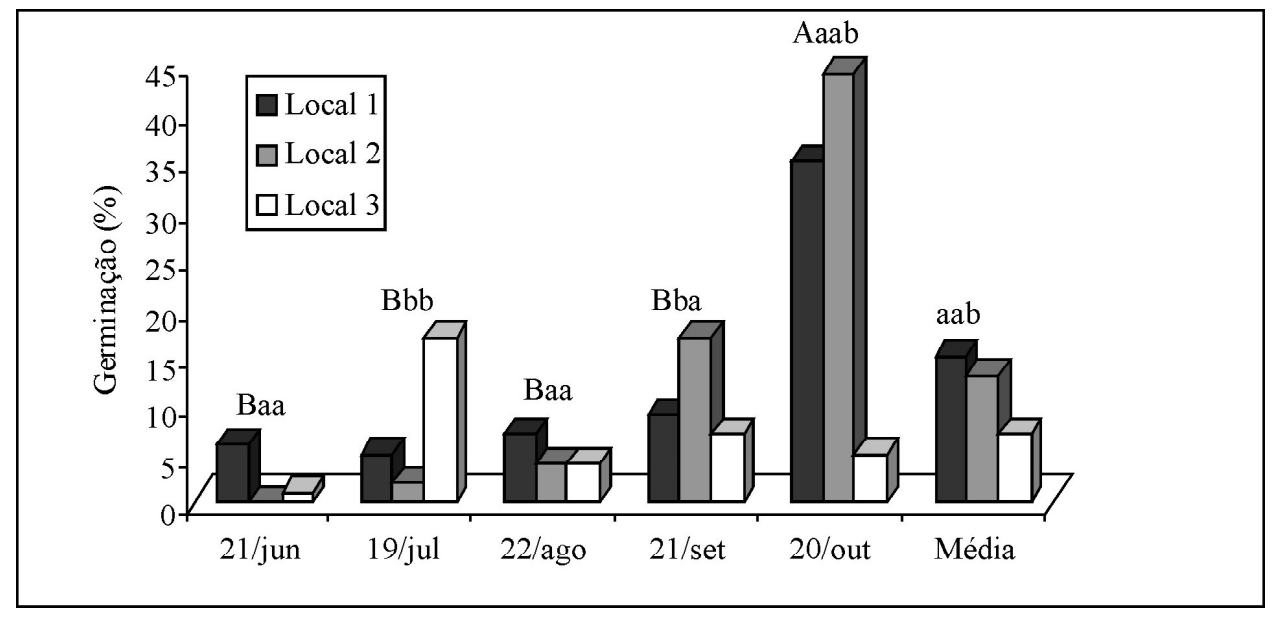

Figura 3 - Germinação de sementes de Syngonanthus elegans em função das épocas e locais de colheita. Médias seguidas pela mesma letra maiúscula entre os tratamentos de épocas de colheita e mesma letra minúscula entre os tratamentos de locais de colheita não diferem entre si $(\mathrm{P}<0,05)$, pelo teste de Tukey. Diamantina, MG, 2006.

Nos locais 1 e 2 o solo bem drenado não proporcionou boas condições para que as plantas atingissem a maturação mais cedo. Ao contrário, contribuiu para alongar o período de desenvolvimento vegetativo, com as sementes entrando em maturação no final de outubro.

A S. elegans apresenta grandes populações e ampla área de distribuição, desde Diamantina até a Serra do Cipó (PARRA, 1998). Scatena et al. (1999a) enfatizam que espécies de Syngonanthus crescem em diferentes condições edáficas, habitando solos secos, úmidos e até alagados e sempre expostas ao sol e que esta espécie ocorrendo e produzindo sementes em hatitats xéricos, poderia favorecer a germinação das sementes sob temperaturas mais elevadas, ou seja, no final do ciclo de produção (outubro), coincidindo com o início do período das chuvas (locais 1 e 2). Em áreas com maior propensão ao acúmulo de água no solo, as plantas encontrariam melhores condições para completarem seu ciclo de desenvolvimento. Entretanto, alta umidade dos solos causa diminuição na amplitude de flutuações térmicas (KLIPS \& PEÑASOLA, 2003) podendo afetar a resposta germinativa 
das sementes produzidas sob tais condições (OLIVEIRA \& GARCIA, 2005), o que foi identificado no local 3. Considerando a diversidade climática e edáfica das áreas de produção de sementes de sempre-viva nos campos rupestres de altitude presume-se que o período de produção e a qualidade fisiológica de sementes de $S$. elegans varia com o local e durante o ciclo de desenvolvimento. Esta condição diferenciada de clima e solo proporciona a distribuição da germinação no espaço e no tempo dessa espécie, pois, dessa forma, é aumentada a possibilidade de recrutamento das plântulas ao longo do ciclo de produção.

O início da dispersão das sementes foi observada na colheita realizada em 21/06/05 e o final em 20/10/05 (última colheita das sementes). Partindo-se da informação de que a dispersão das sementes ocorre nos meses de junho a outubro, ou seja, muito depois do início das colheitas realizadas, quando os capítulos destacam-se pela alvura (março e abril), conclui-se que esta antecipação antes da dispersão é danosa, porque poucas plantas terão chances de produzirem sementes e, afeta, portanto, fortemente o recrutamento de novos indivíduos na população (BEDÊ, 2002). O resultado dessa situação está sendo presenciado pelas populações que dela tiram os seus lucros: extinção das áreas naturais de sempre-viva, sobresforço de coleta (GIULIETTI et al., 1988) diminuição das exportações e abandono da atividade.

Informações como o período de produção e dispersão das sementes são importantes para o conhecimento do hábito dessa espécie e servem de base para o desenvolvimento de estratégias de manejo e multiplicação. Programas de colheita planejada deverão ser implementados de forma que não sejam colhidas todas as plantas nas áreas de ocorrência natural, permitindo o repovoamento pelas remanescentes. É essencial a orientação dos colhedores para a necessidade de dispersão das sementes e que, para isso, as plantas podem e devem ser colhidas mais tardiamente e com os capítulos totalmente abertos. Para áreas com o objetivo de multiplicação deverá ser observada e monitorada a época de colheita visando a obter sementes em maior volume e com maior qualidade fisiológica.

Devido a grande importância que representa para Diamantina e região todo esforço da pesquisa, do pessoal técnico, de estudantes e da comunidade, serão imprescindíveis para o desenvolvimento de práticas seguras e embasadas em princípios ecológicos que garantirão a sobrevivência da espécie e a continuidade dessa atividade comercial.

\section{CONCLUSÕES}

A qualidade fisiológica de sementes de S. elegans varia em função da época e local de colheita.

Estratégias de manejo devem ser realizadas como a colheita após o início do período de dispersão das sementes (junho a outubro) e com os capítulos totalmente abertos.

\section{AGRADECIMENTOS}

À Fundação de Amparo à Pesquisa do Estado de Minas Gerais (FAPEMIG) pela concessão de bolsa de iniciação científica e auxílio financeiro na compra de equipamentos.

\section{REFERÊNCIAS BIBLIOGRÁFICAS}

BEDÊ, L. C. Busca de alternativas para uso sustentado de sempre-vivas na região de Diamantina, MG: estudo dos efeitos decorrentes do manejo extrativista sobre a dinâmica populacional de Syngonanthus elegans var. elenatus (Eriocaulaceae). Belo Horizonte: UFMG, 2002. 17 p. Relatório técnico.

BRASIL. Ministério da Agricultura, do Abastecimento e da Reforma Agrária. Secretaria Nacional de Defesa Agropecuária. Regras para análise de sementes. Brasília, DF, $1992.365 \mathrm{p}$.

COAN, A. J.; SCATENA, V. L.; GIULIETTI, A. M. Anatomia de algumas espécies aquáticas de Eriocaulaceae brasileiras. Acta Botanica Brasílica, Porto Alegre, v. 16, p. 371-384, 2002.

EMPRESA BRASILEIRA DE PESQUISA AGROPECUÁRIA. Centro Nacional de Pesquisas de Solos. Sistema brasileiro de classificação de solos. Rio de Janeiro, 2006. $306 \mathrm{p}$.

GIULIETTI, A. M.; WANDERLEY, M. G. L.; LONGHIWAGNER, H. M.; PIRANI, J. R.; PARRA, L. R. Estudos em "sempre-vivas": taxonomia com ênfase nas espécies de Minas Gerais, Brasil. Acta Botanica Brasílica, Porto Alegre, v. 10, p. 329-384, 1996.

GIULIETTI, N.; GIULIETTI, A. M.; PIRANI, J. R.; MENEZES, N. L. Estudos de sempre-vivas: importância econômica do extrativismo em Minas Gerais, Brasil. Acta Botanica Brasílica, Porto Alegre, v. 1, n. 2, p. 179-192, 1988.

INSTITUTO NACIONAL DE METEOROLOGIA. INMET. Disponivel em: $\langle$ hittp:///www.inmet.gov.bri . Acesso em: 20 abr. 2006. 
KLIPS, A. R.; PENÃSOLA, J. The timing of seed fall, innate dormancy, and ambient temperature in Lythrum salicaria. Aquatic Botany, [S.1.], v. 75, p. 1-7, 2003.

KRAUS, J. E.; SCATENA, V. L.; LEWINGER, M. E.; TRENCH, K. U. Morfologia externa e interna de quatro espécies de Paepalanthus Kunth (Eriocaulaceae) em desenvolvimento pós-seminal. Boletim de Botânica da Universidade de São Paulo, São Paulo, v. 15, p. 45-53, 1996.

MENDONÇA, M. P.; LINS, L. V. Lista vermelha das espécies ameaçadas de extinção da flora de Minas Gerais. Belo Horizonte: Fundação Biodiversitas/Fundação ZooBotânica de Belo Horizonte, 2000.

OLIVEIRA, P. G.; GARCIA, Q. S. Efeitos da luz e da temperatura na germinação de sementes de Syngonanthus elegantulus Ruhland, S. elegans (Bong.) Ruhland e $S$. venustus Silveira (Eriocaulaceae). Acta Botanica Brasílica Porto Alegre, v. 19, n. 3, p. 639-645, 2005.

ORIANI, A.; SCATENA, V. L.; SANO, P. T. Anatomia das folhas, brácteas e escapos de Actinocephalus (Koern.) Sano (Eriocaulaceae). Revista Brasileira de Botânica, Viçosa, v. 28, n. 2, p. 229-240, 2005.

PAIXÃO-SANTOS, J. da; DORNELLES, A. L. C.; SILVA, J. R. dos S.; RIOS, A. P. Germinação in vitro de Syngonanthus mucugensis Giulietti. Sitientibus Série Ciência Biológicas, [S.1.], v. 3, n. 1/2, p. 120-124, 2003.

PARRA, J. R. Flora da Serra do Cipó, Minas Gerais: Syngonanthus Ruhland (Eriocaulaceae). Boletim de Botânica da Universidade de São Paulo, São Paulo, v. 17, p. 219-252, 1998.
SANO, P. T. Actinocephalus (Koern.) Sano (Paepalanthus sect. Actinocephalus), a new genus of Eriocaulaceae, and other taxonomic and nomeclatural changes involving Paepalanthus Mart. Táxon, [S.1.], v. 53, p. 99-107, 2004.

SCATENA, V. L.; CARDOSO, V. A.; GIULIETTI, A. M. Morfoanatomia de espécies de Blastocaulon Ruhland (Eriocaulaceae). Acta Botanica Brasílica, Porto Alegre, v. 13, p. 29-41, 1999a.

SCATENA, V. L.; GIULIETTI, A. M.; CARDOSO, V. A. Anatomia de raízes, escapos e folhas de espécies de Eriocaulon L. (Eriocaulaceae). Boletim de Botânica da Universidade de São Paulo, São Paulo, v. 18, p. 11-20, 1999 b.

SCATENA, V. L.; LEMOS FILHO, J. P.; LIMA, A. A. A. Morfologia do desenvolvimento pós-seminal de Syngonanthus elegans e S. niveus (Eriocaulaceae). Acta Botanica Brasílica, Porto Alegre, v. 10, p. 85-91, 1996.

SCATENA, V. L.; MENEZES, N. L. Anatomia dos escapos e folhas de Syngonanthus Ruhl. (Eriocaulaceae) de Campos rupestres. Revista Brasileira de Biologia, São Paulo, v. 56, p. 317-332, 1996.

SCATENA, V. L.; ROSA, M. M. Morphology and anatomy of the vegetative organs ands scapes from Aphorocaulon (Paepalanthus, Eriocaulaceae). Brazilian Archives of Biology and Technology, Curitiba, v. 44, p. 49-58, 2001.

SCATENA, V. L.; VICH, D. V.; PARRA, L. R. Anatomia de escapos, folhas e brácteas de Syngonanthus sect. Eulepis (Bong. Ex Koern.) Ruhland (Eriocaulaceae). Acta Botanica Brasilica, Porto Alegre, v. 18, n. 4, p. 1-12, 2004. 